\title{
An in situ transmission electron microscope investigation into grain growth and ordering of sputter-deposited nanocrystalline $\mathrm{Ni}_{3} \mathrm{Al}$ thin films
}

\author{
H.P. $\mathrm{Ng}^{\mathrm{a})}$ and A.H.W. Ngan \\ Department of Mechanical Engineering, The University of Hong Kong, Pokfulam Road, Hong Kong, \\ People's Republic of China
}

(Received 10 March 2002; accepted 28 May 2002)

The grain growth kinetics and ordering behavior of direct-current magnetron sputter-deposited $\mathrm{Ni}_{75 \text { at.\% }} \mathrm{Al}_{25 \text { at.\% }}$ alloy films were investigated using in situ isothermal annealing in a transmission electron microscope. Both normal and abnormal grain growth modes were observed. The normal grain growth kinetics under isothermal heating from 300 to $700{ }^{\circ} \mathrm{C}$ were found to comply with the Burke law $\dot{d}=\mathrm{K} / d^{\mathrm{n}-1}$, where $d$ is grain size and $\mathrm{K}$ and $\mathrm{n}$ are constants with respect to time. The grain boundary mobility parameter $\mathrm{K}$ was found to obey an Arrehnius rate law with an apparent activation energy of $1.6 \mathrm{eV}$, and $\mathrm{n}$ was found to increase gradually from 5.2 at $300{ }^{\circ} \mathrm{C}$ to 8.7 at $700{ }^{\circ} \mathrm{C}$. Abnormal grain growth occurred at $500{ }^{\circ} \mathrm{C}$ or higher, and grain coalescence was identified as an important operative mechanism. It was also observed that the initially as-deposited state of the films was crystalline with a disordered face-centered-cubic structure, but ordering into the equilibrium $\mathrm{L1}_{2}$ intermetallic structure followed from annealing at temperatures above approximately $500{ }^{\circ} \mathrm{C}$.

\section{INTRODUCTION}

Intermetallic films are being actively investigated for potential use as functional coatings for engineering applications ranging from aeroengines to microelectronic devices. Numerous studies have been dedicated to intermetallic aluminide coatings in the last few years, with substantial attention paid to the mechanical properties and high temperature oxidation resistance of $\mathrm{Fe}-\mathrm{Al}$, $\mathrm{Ni}-\mathrm{Al}$, and Ti-Al-based coatings. ${ }^{1-7}$ For instance, the present authors and $\mathrm{Xu}$ et al. have reported that $\mathrm{Ni}_{3} \mathrm{Al}$ coatings can provide Ni-based alloys with significantly improved surface strength, ${ }^{3,4}$ as well as effective protection from thermal oxidation. ${ }^{3}$ Similarly, Leyens et al. showed that $\mathrm{Ti}-\mathrm{Al}$-based coatings exhibit a variety of beneficial properties on the oxidation, creep, and fatigue of TIMETAL 1100 high temperature alloys. ${ }^{5,6,8}$ On the other hand, the metallization of semiconductors by intermetallic aluminides like $\mathrm{Ni}-\mathrm{Al}$ and $\mathrm{Ti}-\mathrm{Al}$ as interconnects represents a growing field of interest in the microelectronic industry. ${ }^{9-11}$

In a recent paper, we demonstrated that direct-current (dc) magnetron sputter-deposited $\mathrm{Ni}_{75 \text { at.\% }} \mathrm{Al}_{25 \text { at.\% }}$ thin films exhibit a phenomenal electrical transition from an insulating state to a conducting state upon mild heating. ${ }^{12}$

\footnotetext{
a) Present address: Laboratoire des Matériaux et du Génie Physique, ENSPG-INPG UM 5628, BP 46, 38402, St. Martin d'Hères, France.
}

The transition effect is found to be reversible with respect to temperature changes, implying that the transition happens at constant microstructure. This is to be distinguished from another effect of electrical resistance variation due to annealing of the film's microstructures. The as-deposited state of the $\mathrm{Ni}_{75 \text { at.\% }} \mathrm{Al}_{25 \text { at.\% }}$ films is known to be nanocrystalline with a typical grain size of the order of a few nanometers. ${ }^{12,13}$ Such a refined nanocrystalline configuration, together with a significant oxygen content measured in the $\mathrm{Ni}_{75 \text { at.\% }} \mathrm{Al}_{25 \text { at.\% }}$ films, is believed to be a factor leading to the observed electrical transition effect. ${ }^{12,14}$

The reversible transition is found to occur over a temperature range from room temperature to about $200{ }^{\circ} \mathrm{C}$, within which grain growth is suppressed. One possible application of the reversible transition effect in nanocrystalline $\mathrm{Ni}_{75 \text { at.\% }} \mathrm{Al}_{25 \text { at.\% }}$ thin films would be as thermal switches in microelectromechanical systems, but the applicability hinges on the thermal stability of the film with respect to grain growth and other microstructural changes. There are at least two reasons why grain growth in nanocrystalline materials can be potentially very different from the situation in conventional large grained materials. The first is the absence of dislocations in the nanocrystalline state, and hence one would not expect recovery or recrystallization to precede grain growth. This point is of crucial importance to processing routes involving ball milling in the powder metallurgy. ${ }^{15} \mathrm{Sec}-$ ondly, the physical dimension of the grain boundaries in 
a nanocrystalline material would limit the formation of conventional second phase particles in large grained materials, and hence the conventional Zener drag mechanism of grain boundary pinning would no longer be applicable. The present paper therefore represents an attempt to study the kinetics of grain growth and ordering in nanocrystalline $\mathrm{Ni}_{75 \text { at.\% }} \mathrm{Al}_{25 \text { at.\% }}$ thin films.

\section{EXPERIMENTAL PROCEDURES}

The Ni-Al thin films were deposited by a dc planar magnetron sputtering device (Bal-Tec MED-020) (BALTEC AG, Balzers, Liechtenstein) with a water-cooled $\mathrm{Ni}-27.4 \% \mathrm{Al}$ alloy target, which is capable of yielding the stoichiometric $\mathrm{Ni}_{3} \mathrm{Al}$ composition through controlling a number of parameters reported elsewhere. ${ }^{3}$ In this work, the base sputtering pressure used was $1 \times 10^{-6}$ mbar or better, compared to the $1 \times 10^{-5} \mathrm{mbar}$ or higher in our previous study. ${ }^{12}$ Commercially pure (>99.5\%) nickel substrates with a thickness of $1 \mathrm{~mm}$ was homogenized at $1000{ }^{\circ} \mathrm{C}$ for $24 \mathrm{~h}$ prior to surface treatments and deposition for all experiments involving postdeposition annealing so that any possible microstructural changes in the substrates that may influence the films could be avoided. The substrates were mechanically ground and polished down to $1 \mu \mathrm{m}$ followed by solvent cleaning in ethyl alcohol and acetone to remove organic contaminations. The in-line target-to-substrate distance was fixed at $80 \mathrm{~mm}$. To ensure the purity of the deposit, the target was presputtered for more than $30 \mathrm{~min}$ with the substrate protected by a shutter before actual deposition on the substrate. The sputtering gas was ultrahigh purity argon (>99.9999\%) at a pressure of $5 \times 10^{-2}$ mbar. All deposition was performed at a sputtering current of 90-100 mA, which is equivalent to a sputtering power of $70 \mathrm{~W}$ or a deposition rate of $2-3 \AA / \mathrm{s}$. No intentional heating was applied to the substrates in the course of deposition, although the plasma discharge would be able to raise the substrate temperature to about $100{ }^{\circ} \mathrm{C}$. The $\mathrm{Ni}_{75 \text { at.\% }} \mathrm{Al}_{25 \text { at.\% }}$ films prepared for the present grain growth analysis were all $2 \mu \mathrm{m}$ in thickness unless otherwise stated.

The film specimens for in situ cross-sectional transmission electron microscopy (XTEM) were prepared using a special "C-Ring" method. In this method, nickel substrates with a semihexagonal cross-section $(2 \mathrm{~mm}$ wide and $30 \mathrm{~mm}$ long) were prepared by electric discharge wire cutting and deposited with $\mathrm{Ni}_{75}$ at.\% $\mathrm{Al}_{25 \text { at.\% }}$ films on their longitudinal surfaces. A pair of such coated substrates were glued together with their coated surfaces facing each other using the Aron-Alpha ${ }^{\circledR}$ instant-glue (Tokyo, Japan). The resultant hexagonal substrate column was then firmly inserted and glued into a tailormade 3-mm-diameter metallic C-ring cylinder bored with a matching hexagonal empty core using the G1 epoxy (Epoxy Technology EPO-TEK 353ND, Billerica, MA), which is specifically for high-temperature transmission electron microscopy (TEM) experiments. The cylindrical assembly was then sectioned by a low-speed diamond saw into roughly $200-\mu \mathrm{m}$-thick discs, followed by gently polishing on the cut surfaces to a thickness of less than $80 \mu \mathrm{m}$. The C-ring here played an important role to protect the films from delamination during slicing or polishing. Prior to thinning, the specimens were soaked in acetone to remove the layer of Aron-Alpha ${ }^{\circledR}$ glue between the films, which would otherwise melt under in situ heating in the TEM. The glue served a temporary purpose to protect the film surface from the intrusion of the G1 epoxy by capillary effect in its fluid state, which could otherwise severely affect the imaging and structural characterization of the cross-sectional films under TEM. Finally, thinning of the discs was performed by twin-jet electropolishing using a mixture of $90 \%$ methanol $+10 \%$ perchloric acid at $5 \mathrm{~V}$ and $-50{ }^{\circ} \mathrm{C}$ to obtain electron transparency near the film-substrate interfaces. Precaution was taken to protect the film from excessive impulse of the jets by sandwiching the specimen in aluminium foils before activating the jet flow. The aluminium foils serve additionally as electrical contacts to bridge the C-ring and the central core, which are otherwise electrically insulated by the epoxy.

Atomic force microscopy (AFM) was applied to characterize the planar surface morphology of the asdeposited $\mathrm{Ni}_{75 \text { at.\% }} \mathrm{Al}_{25 \text { at.\% }}$ films. AFM scanning was performed in the contact mode using a Digital Instruments Nanoscope IIIA controlled microscope (Santa Barbara, CA). In situ TEM heat treatments of the specimens were carried out on an Oxford resistive hot-stage in a JOEL 2000FX TEM (Tokyo, Japan) operated at $200 \mathrm{kV}$. To study the grain growth kinetics as a function of time and temperature, dynamic microstructural observations were carried out on the XTEM specimens during a series of isothermal in situ heat treatments, each lasting for approximately $50 \mathrm{~min}$ and at different temperatures up to the nominal instrumental limit of $800^{\circ} \mathrm{C}$. A constant heating rate of $20^{\circ} \mathrm{C} / \mathrm{min}$ was used for all temperature increments throughout.

The determination of grain size was performed on digitized XTEM micrographs with the aid of an image analyzer software. The experimental grain size distributions were fitted with Gaussian distributions, and the Gaussian mean and standard deviation were computed. Crystallographic information of the nanocrystalline $\mathrm{Ni}_{75 \text { at.\% }} \mathrm{Al}_{25 \text { at.\% }}$ films were obtained by selected area diffraction (SAD). The lattice constant $a$ is deduced from the observable diffraction rings or diffraction spots on a SAD pattern according to the relationship

$$
\frac{\sqrt{h^{2}+k^{2}+l^{2}}}{a}=\frac{x_{h k l}}{\mathrm{~L} \lambda}
$$


where $(h k l)$ is the diffraction plane indices, $x_{h k l}$ the radii of the diffraction rings, $L$ the camera length, and $\lambda$ the electron wavelength. The values of $x_{h k l}$ were measured using the software ProcessDiffraction ${ }^{16}$ (Research Institute for Technical Physics and Materials Science, Budapest, Hungary) on SAD patterns digitized at a resolution of $300 \mathrm{dpi}$, which offers an equivalent instrumental resolution of better than $85 \mu \mathrm{m}$ on a photographic print.

\section{RESULTS}

\section{A. Nanocrystalline structure and composition of as-deposited $\mathrm{Ni}_{\mathbf{7 5} \text { at.\% }} \mathrm{Al}_{\mathbf{2 5}}$ at.\% films}

The surface topography of an as-deposited $\mathrm{Ni}_{75 \text { at.\% }} \mathrm{Al}_{25 \text { at.\% }}$ thin film deposited on nickel substrate as revealed by AFM is show in Fig. 1(a). The film appears to be composed of nanograins with grain diameters of the order of $10 \mathrm{~nm}$. Figure 1(b) shows a typical XTEM micrograph of the $\mathrm{Ni}_{75 \text { at.\% }} \mathrm{Al}_{25 \text { at.\% }}$ film near the film and substrate interface, indicating the actual size of the constituent nanocrystallites to be within 5 to $10 \mathrm{~mm}$ in the as-deposited state. The relative compositions of $\mathrm{Ni}$ and $\mathrm{Al}$ in the films were determined by energy dispersive $\mathrm{x}$-ray (EDX) analysis to be fluctuating about the stoichiometric ratio of $3: 1$ within \pm 0.5 at.\%. A typical EDX spectrum illustrating the overall chemical composition of a $\mathrm{Ni}_{75 \text { at.\% }} \mathrm{Al}_{25 \text { at.\% }}$ film is given in Fig. 2. In addition to the $\mathrm{Ni}$ and $\mathrm{Al}$ peaks, a prominent oxygen peak at $0.523 \mathrm{keV}$, with an intensity comparable to those of the $\mathrm{Ni}$ and $\mathrm{Al}$ counterparts in the spectrum, can be observed. Such a significant oxygen content has been consistently observed in our $\mathrm{Ni}_{75 \text { at.\% }} \mathrm{Al}_{25 \text { at.\% }}$ films despite the use of a high base vacuum of approximately $10^{-6} \mathrm{mbar}$ in conjunction with ultrahigh purity argon as the sputtering gas in our film deposition process.

\section{B. Grain growth and microstructure evolution during in situ annealing in TEM}

Figure 3 shows the grain size distributions of film at different stages of isothermal heat-treatments at temperatures ranging from 300 to $700{ }^{\circ} \mathrm{C}$. The annealing time given in Fig. 3 was measured from the onset of attainment of the set-point temperature and is used here to indicate the grain growth rate after the set-point temperature was reached. In heat-treatments at high temperatures such as $700^{\circ} \mathrm{C}$, significant grain growth had already occurred before the set point temperature was reached, and so the time used in Fig. 3 does not correspond to the actual time lapsed from the onset of grain growth. The grain size distributions at $300{ }^{\circ} \mathrm{C}$ [Fig. 3(a)] follow a nearly symmetrical bell shape and can be satisfactorily fitted by Gaussian distributions. Normal grain growth, represented by a steady shift of the overall population to the right side of the graphs as time increases, can be seen to be the dominating growth behavior of the $\mathrm{Ni}-\mathrm{Al}$ film in the lower temperature regime. However, abnormal grain growth became operative at $500{ }^{\circ} \mathrm{C}$ [Fig. 3(b)], where a minor population of large grains started to emerge after $30 \mathrm{~min}$ of annealing. The coexistence of normal and abnormal grain growth is well demonstrated in the histograms at $700{ }^{\circ} \mathrm{C}$ [Fig. 3(c)], where the distributions are clearly bimodal. The fast rate of abnormal grain growth at $700{ }^{\circ} \mathrm{C}$ is evidenced by the speedy propagation of the second peak from initially at approximately $55 \mathrm{~nm}$ to finally at approximately $90 \mathrm{~nm}$ in $25 \mathrm{~min}$ of annealing. The normal grain growth behavior, on the other hand, showed a much milder grain size increment during a comparable period of time.

To characterize the normal grain growth behavior, the Gaussian mean grain size $d$ and the standard deviation for grains growing normally were measured from the fitted Gaussian distributions of the grain growth histograms after the abnormal growth peaks were ignored when they occurred, and these data are summarized in Table I. The

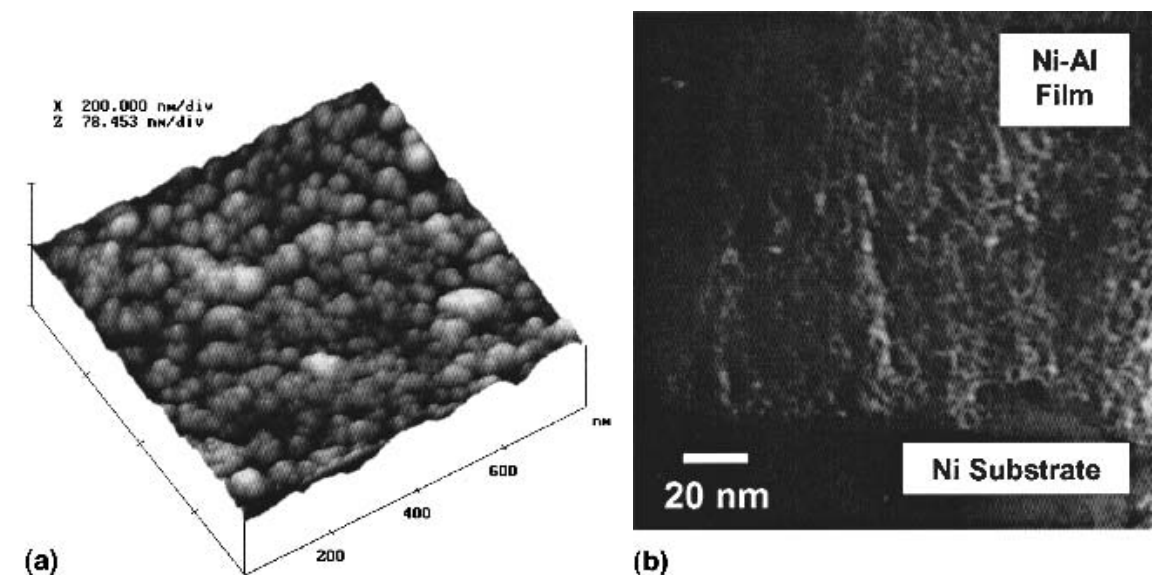

FIG. 1. Typical nanocrystalline structure of the as-sputtered $\mathrm{Ni}_{75 \text { at.\% }} \mathrm{Al}_{25 \text { at.\% }}$ film revealed by (a) $\mathrm{AFM}$ and (b) XTEM imaging. 
small difference in the mean grain size between the preannealed state and the early stages of annealing at $300{ }^{\circ} \mathrm{C}$ (both 7.2-7.3 nm) suggests that grain growth is insignificant below and up to $300{ }^{\circ} \mathrm{C}$. Upon heat treatment at a higher temperature, on the other hand, steady normal grain growth occurred, corresponding to a continuous increase in the mean grain size from slightly larger than $7 \mathrm{~nm}$ in the as-deposited state to about $19 \mathrm{~nm}$ towards the end of the $700{ }^{\circ} \mathrm{C}$ heat treatment.

Figure 4 illustrates the evolution of the nanocrystalline structure of the $\mathrm{Ni}_{75 \text { at.\% }} \mathrm{Al}_{25 \mathrm{at} . \%}$ film at different stages of the isothermal annealing process. It is evident in the figure that the overall grain size remained fairly uniformly distributed up to a temperature of $400{ }^{\circ} \mathrm{C}$.

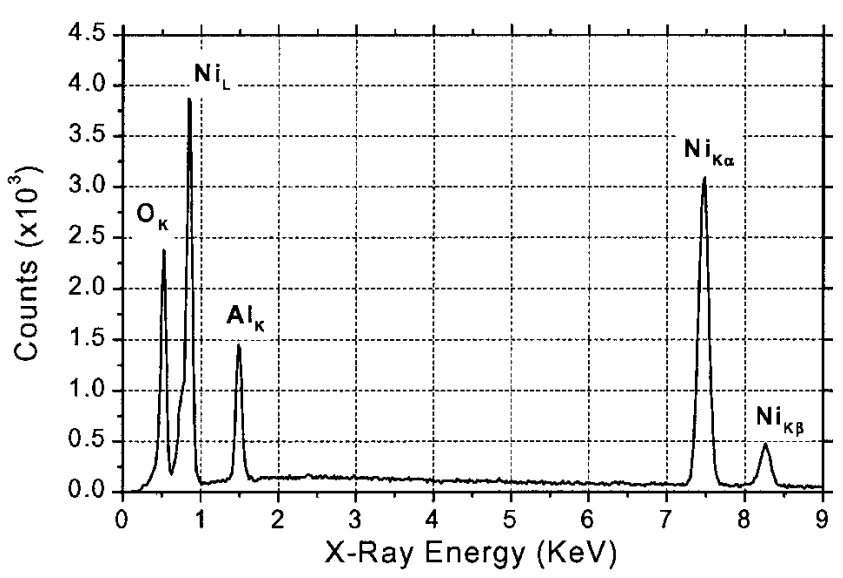

FIG. 2. Energy dispersive $\mathrm{x}$-ray (EDX) spectrum showing the typical chemical composition of a $\mathrm{Ni}_{75 \text { at.\% }} \mathrm{Al}_{25 \text { at.\% }}$ film as-deposited by magnetron sputtering. The prominent $\mathrm{O}_{\mathrm{K}}$ peak observed in the spectrum is indicative of a significant oxygen inclusion in the $\mathrm{Ni}-\mathrm{Al}$ film during the deposition process.
Beyond $600{ }^{\circ} \mathrm{C}$, abnormal grain growth became significant at a few locations where grains several times larger than the average size had developed quite suddenly out of the matrix. Examples can be found in Fig. 4(f) at locations pointed at by arrows, where several abnormal grains (over $100 \mathrm{~nm}$ in diameter) emerged after 25 min of annealing at $700{ }^{\circ} \mathrm{C}$. Figure 5 illustrates the microstructure of a $\mathrm{Ni}_{75 \text { at.\% }} \mathrm{Al}_{25 \text { at.\% }}$ film undergoing extensive, abnormal grain growth after prolonged annealing at $700{ }^{\circ} \mathrm{C}$. A highly nonuniform grain size distribution resulted.

Figure 6 shows the microstructural evolution in the XTEM specimen after 15 and $45 \mathrm{~min}$ of isothermal treatment at $500{ }^{\circ} \mathrm{C}$, during which abnormal grain growth was about to begin. A tendency can be observed in the figures for the nanograins to coalesce to form larger grains of a few tens of nanometers. Grain coalescence was indeed observed to be the main mechanism responsible for the accelerated grain growth at high temperatures. Figures 7(a)-7(1) capture the morphological changes during coalescence between a pair of adjacent nanocrystals. Interestingly, periodic and alternative changes in the image contrast were found to occur between both grains, i.e., at first the upper crystal appeared darker than the lower one in Figs. 7(b)-7(d), but then the lower one became darker than the upper one in Figs. 7(f)-7(j). The contrast variation of the grains was also accompanied by slow flickering of the corresponding diffraction patterns, which are not shown here, and this indicates rotations of crystallographic orientations of the grains within a small angular range. The final amalgamation into a single larger grain is shown in Figs. 7(k) and 7(l), in which the combined grain exhibited a well-defined border with no observable interior interface.


FIG. 3. Grain size distribution change of $\mathrm{Ni}_{75 a t . \%} \mathrm{Al}_{25 \text { at. \% }}$ films during isothermal heat treatments respectively at (a) $300{ }^{\circ} \mathrm{C}$, (b) $500{ }^{\circ} \mathrm{C}$, and (c) $700{ }^{\circ} \mathrm{C}$, indicating an abnormal grain growth associated with the latter. 
TABLE I. The grain size measured for a $\mathrm{Ni}_{75 \mathrm{at} . \%} \mathrm{Al}_{25 \text { at.\% }}$ film during a series of isothermal annealing at various temperatures.

\begin{tabular}{|c|c|c|c|c|c|c|c|c|c|c|c|}
\hline \multicolumn{3}{|c|}{$300^{\circ} \mathrm{C}$} & \multicolumn{3}{|c|}{$400^{\circ} \mathrm{C}$} & \multicolumn{3}{|c|}{$500^{\circ} \mathrm{C}$} & \multicolumn{3}{|c|}{$700^{\circ} \mathrm{C}$} \\
\hline $\begin{array}{l}\text { Time } \\
\text { (min) }\end{array}$ & $\begin{array}{c}d \\
(\mathrm{~nm})\end{array}$ & $\begin{array}{l}\text { s.d. } \\
(\mathrm{nm})\end{array}$ & $\begin{array}{l}\text { Time } \\
(\mathrm{min})\end{array}$ & $\begin{array}{c}d \\
(\mathrm{~nm})\end{array}$ & $\begin{array}{l}\text { s.d. } \\
\text { (nm) }\end{array}$ & $\begin{array}{l}\text { Time } \\
(\mathrm{min})\end{array}$ & $\begin{array}{c}d \\
(\mathrm{~nm})\end{array}$ & $\begin{array}{l}\text { s.d. } \\
(\mathrm{nm})\end{array}$ & $\begin{array}{l}\text { Time } \\
(\mathrm{min})\end{array}$ & $\begin{array}{c}d \\
(\mathrm{~nm})\end{array}$ & $\begin{array}{l}\text { s.d. } \\
(\mathrm{nm})\end{array}$ \\
\hline 15 & 7.301 & 1.014 & 20 & 9.149 & 1.367 & 15 & 10.576 & 1.428 & 15 & 17.095 & 4.271 \\
\hline 30 & 8.487 & 0.870 & 35 & 9.526 & 1.489 & 30 & 11.313 & 2.093 & 25 & 17.584 & 5.565 \\
\hline 45 & 8.981 & 1.621 & 50 & 10.530 & 1.541 & 45 & 12.153 & 2.200 & 40 & 19.156 & 6.910 \\
\hline
\end{tabular}

As-deposited mean grain size $=7.235 \mathrm{~nm}($ s.d. $=0.881)$

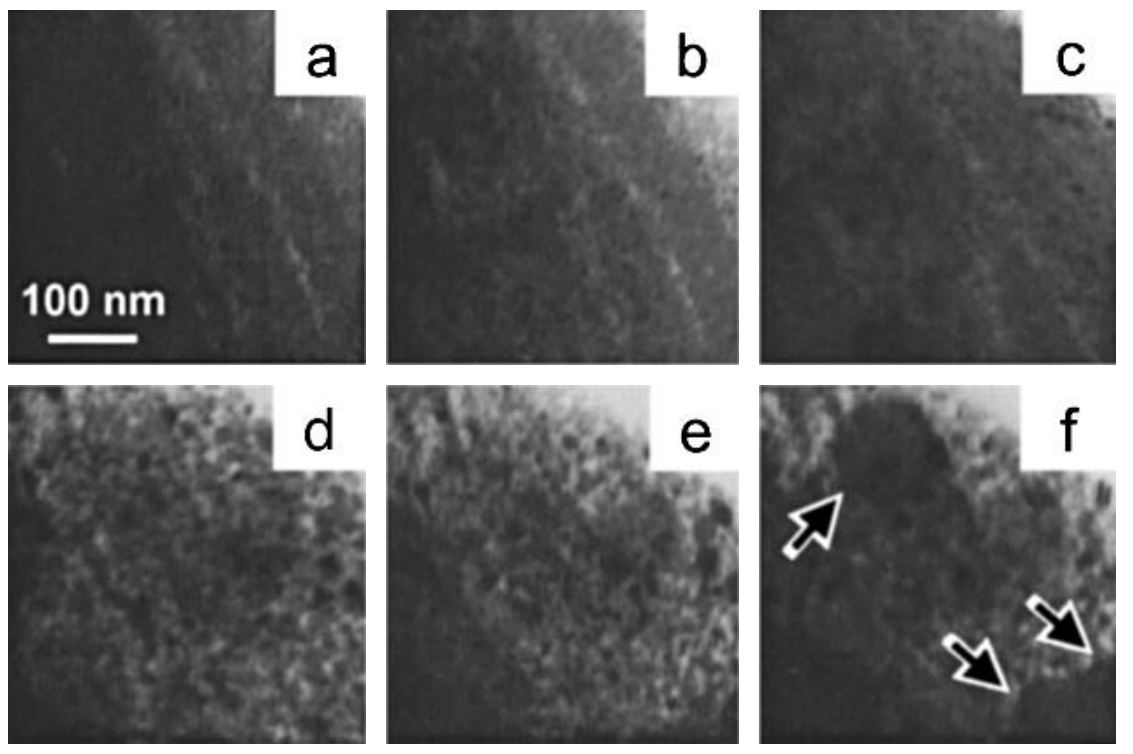

FIG. 4. XTEM micrographs showing the progressive development of the overall nanogranular structure of $\mathrm{Ni}_{75 \text { at.\% }} \mathrm{Al}_{25 \text { at.\% }}$ films at different stages of the heat treatment process: (a) before annealing, (b) at $300{ }^{\circ} \mathrm{C}$ for $30 \mathrm{~min}$, (c) at $400{ }^{\circ} \mathrm{C}$ for $35 \mathrm{~min}$, (d) at $500{ }^{\circ} \mathrm{C}$ for $35 \mathrm{~min}$, (e) at $600{ }^{\circ} \mathrm{C}$ for $40 \mathrm{~min}$, and (f) at $700{ }^{\circ} \mathrm{C}$ for $25 \mathrm{~min}$.

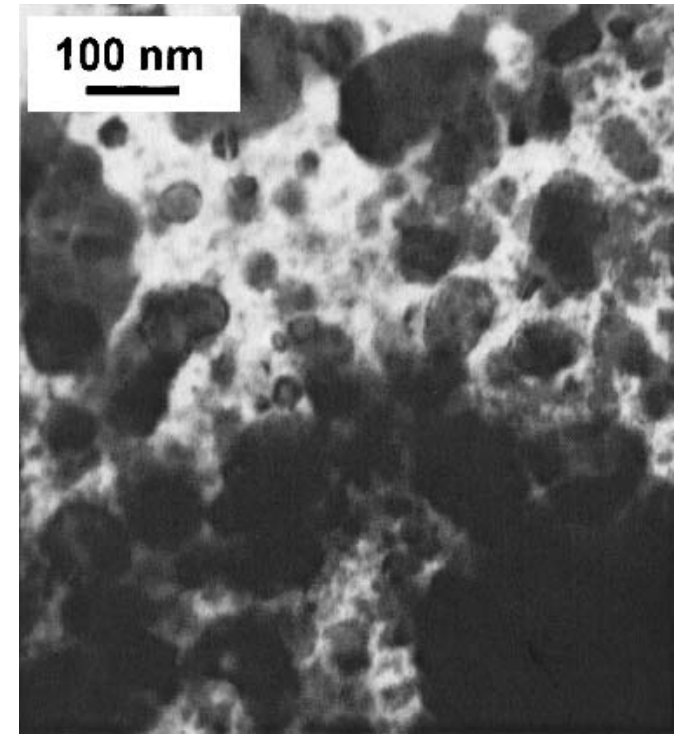

FIG. 5. XTEM of film microstructure after abnormal grain growth at $700{ }^{\circ} \mathrm{C}$.
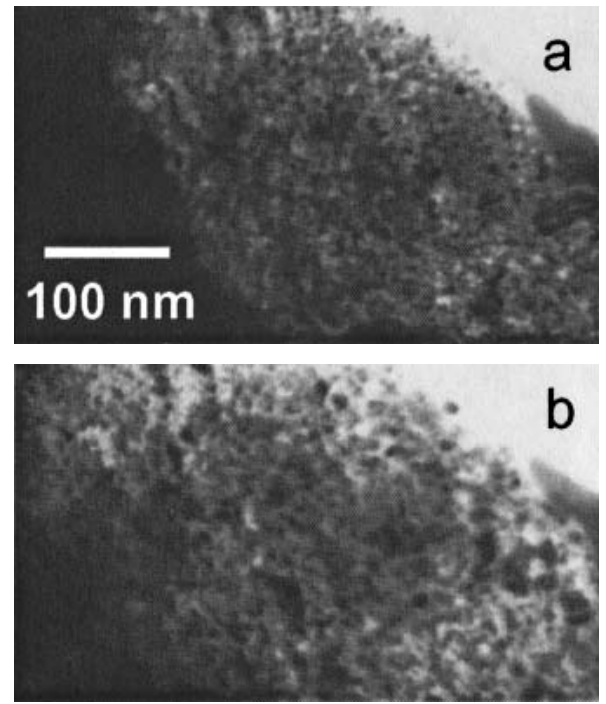

FIG. 6. XTEM micrographs showing the microstructural changes of a $\mathrm{Ni}_{75 \text { at.\% }} \mathrm{Al}_{25 \text { at.\% }}$ film from an annealing time of (a) 15 min to (b) $45 \mathrm{~min}$ at $500{ }^{\circ} \mathrm{C}$, during which coalescence of nanocrystals occurred. 


\section{Growth kinetics analysis}

Figure 8 shows the log-log plot of the Gaussian mean grain size during normal grain growth $(d)$ versus time $(t)$ during isothermal annealing at different temperatures. It can be seen that the isothermal grain growth approximately obeys the law $d \propto t^{1 / \mathrm{n}}$, where $\mathrm{n}$ is a constant. This relationship is consistent with the conventional grain growth law due to Burke ${ }^{17}$ :

$$
\dot{d}=\mathrm{K} / d^{\mathrm{n}-1},
$$

where $\mathrm{K}$ is the grain-boundary mobility parameter. Integrating Eq. (2) gives $d^{\mathrm{n}}=d_{\mathrm{o}}^{\mathrm{n}}=\mathrm{Kn} t$, where $d_{\mathrm{o}}$ is the initial grain size, and if $d_{\mathrm{o}}^{\mathrm{n}}$ is negligible compared with $d^{\mathrm{n}}$, this becomes

$$
\ln (d)=\frac{1}{\mathrm{n}} \ln (t)+\frac{1}{\mathrm{n}} \ln (\mathrm{Kn})
$$

Thus from the slopes and intercepts of the best straight lines in Fig. 8, the constants $\mathrm{n}$ and $\mathrm{K}$ can be obtained at each annealing temperature. The value of $n$ is found to increase gradually from 5.2 at $300^{\circ} \mathrm{C}$ to 8.7 at $700^{\circ} \mathrm{C}$. Burke ${ }^{17}$ further proposed that the constant $\mathrm{K}$ contains the Boltzmann factor, i.e.,

$$
\mathrm{K}=\mathrm{K}_{\mathrm{o}} \exp \left(-\frac{Q}{\mathrm{k} T}\right),
$$

where $\mathrm{K}_{\mathrm{o}}$ is constant, $Q$ is the activation energy for grain growth, and $\mathrm{k}$ and $T$ have their usual meanings. In Fig. 9 are shown the Arrehnius plot of $\mathrm{K}$ versus $1 / T$, from which it can be seen that Eq. (4) is verified. The activation energy estimated from the slope in Fig. 8 is about $1.6 \mathrm{eV}$.

\section{Ordering and crystallographic transformations}

Despite the fact that the $\mathrm{Ni}_{75 \text { at. } \%} \mathrm{Al}_{25 \text { at.\% }}$ films possess a Ni-to-Al atomic ratio that would fall within the phase field of the $\mathrm{Ni}_{3} \mathrm{Al}$ compound in the bulk condition, previous observations have shown that the low-temperature as-deposited nanocrystalline $\mathrm{Ni}_{75 \text { at.\% }} \mathrm{Al}_{25 \text { at.\% }}$ films have a disordered face-centered-cubic (fcc) crystal structure
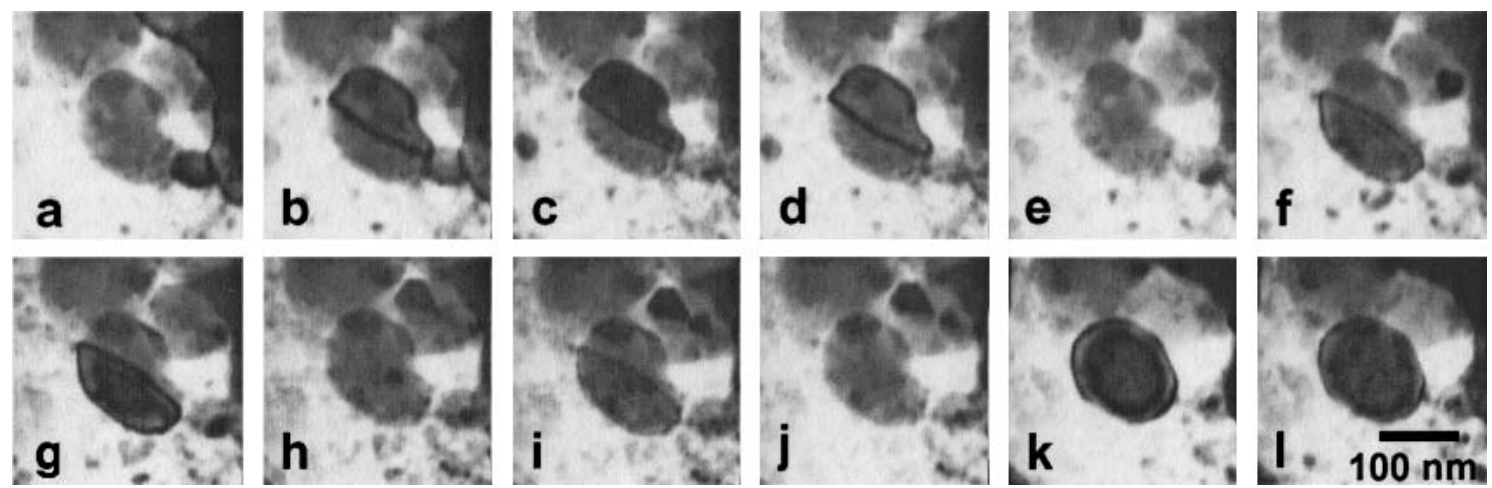

FIG. 7. The sequence of grain coalescence recorded for a $\mathrm{Ni}_{75 \mathrm{at} . \%} \mathrm{Al}_{25 \mathrm{at} . \%}$ film at $800{ }^{\circ} \mathrm{C}$ during a constant time interval of $30 \mathrm{~s}$. Note the periodic changes in image contrast, which corresponds to grain rotations prior to the merging.



FIG. 8. Log-log plot of the Gaussian mean grain size of the $\mathrm{Ni}_{75 \text { at.\% }} \mathrm{Al}_{25 \text { at.\% }}$ nanocrystals against the time of isothermal annealing performed at various temperatures.

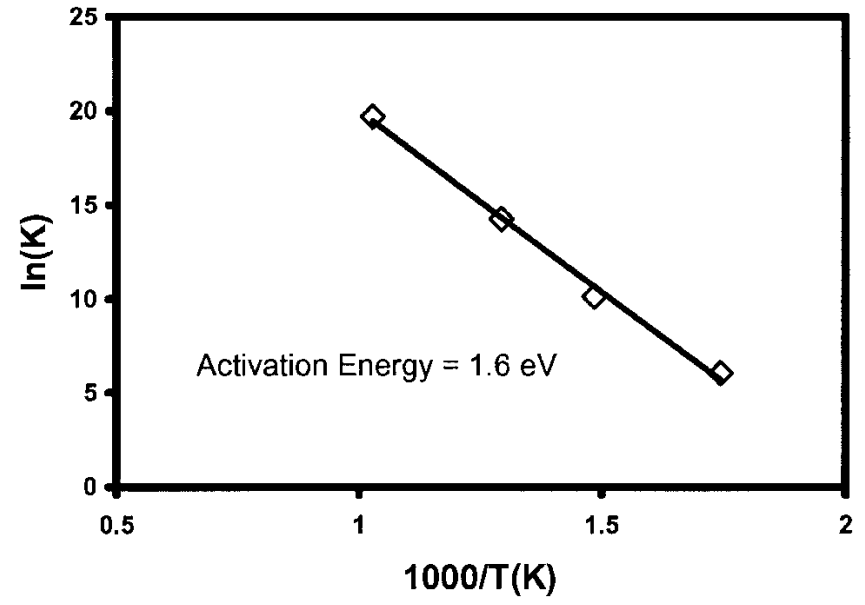

FIG. 9. Arrehnius plot of the grain-boundary mobility parameter. 
instead. ${ }^{12}$ The minimum temperature required to initiate ordering into the equilibrium $\mathrm{L}_{2}$ structure was previously found to be around $500{ }^{\circ} \mathrm{C}-700{ }^{\circ} \mathrm{C},{ }^{12,18}$ depending on the fabrication techniques and processing conditions. In the present work, $500{ }^{\circ} \mathrm{C}$ was found to be an adequate temperature to trigger the ordering of the $\mathrm{Ni}_{75 \text { at.\% }} \mathrm{Al}_{25 \text { at.\% }}$ nanocrystallites inside the TEM.
The crystallographic transformation of the $\mathrm{Ni}-\mathrm{Al}$ film during isothermal annealing at $500{ }^{\circ} \mathrm{C}$ is indicated by the changes of the SAD patterns shown in Fig. 10. The initial crystal structure of the $\mathrm{Ni}_{75 \text { at.\% }} \mathrm{Al}_{25 \text { at.\% }}$ film is evidently disordered fcc, as suggested by the ringlike SAD pattern and the absence of superlattice reflections. By assuming a cubic crystal structure, the linear fit of

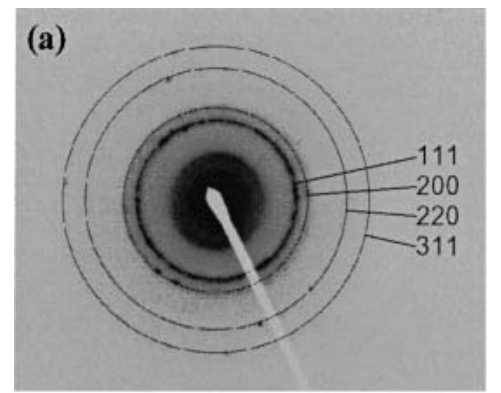

$\mathrm{t}=0 \mathrm{~min} ; a=3.5899 \AA$

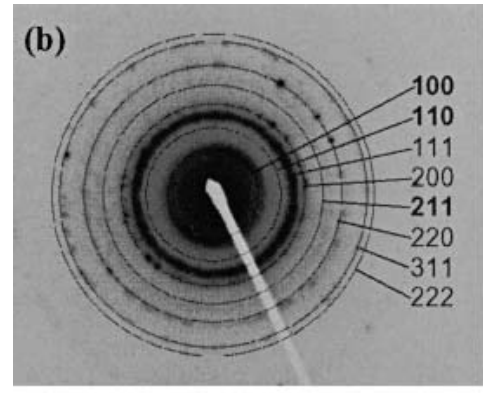

$\mathrm{t}=20 \mathrm{~min} ; a=3.6015 \AA$

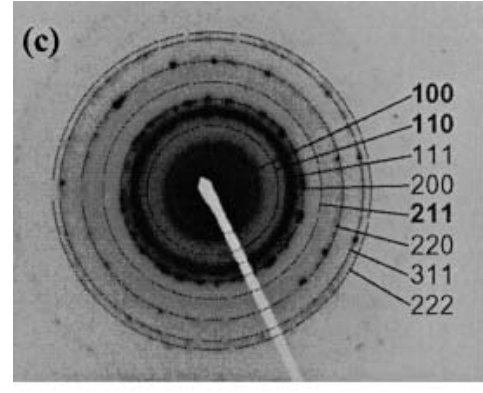

$\mathrm{t}=65 \mathrm{~min} ; a=3.6258 \AA$

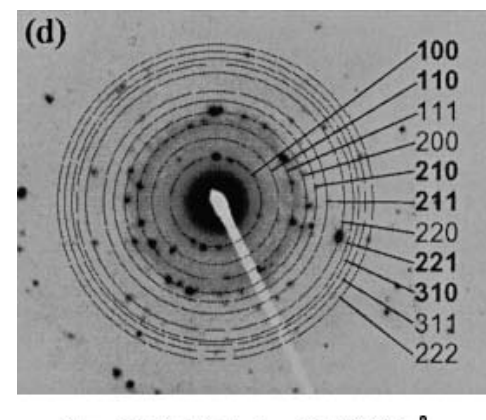

$\mathrm{t}=165 \mathrm{~min} ; a=3.6537 \AA$
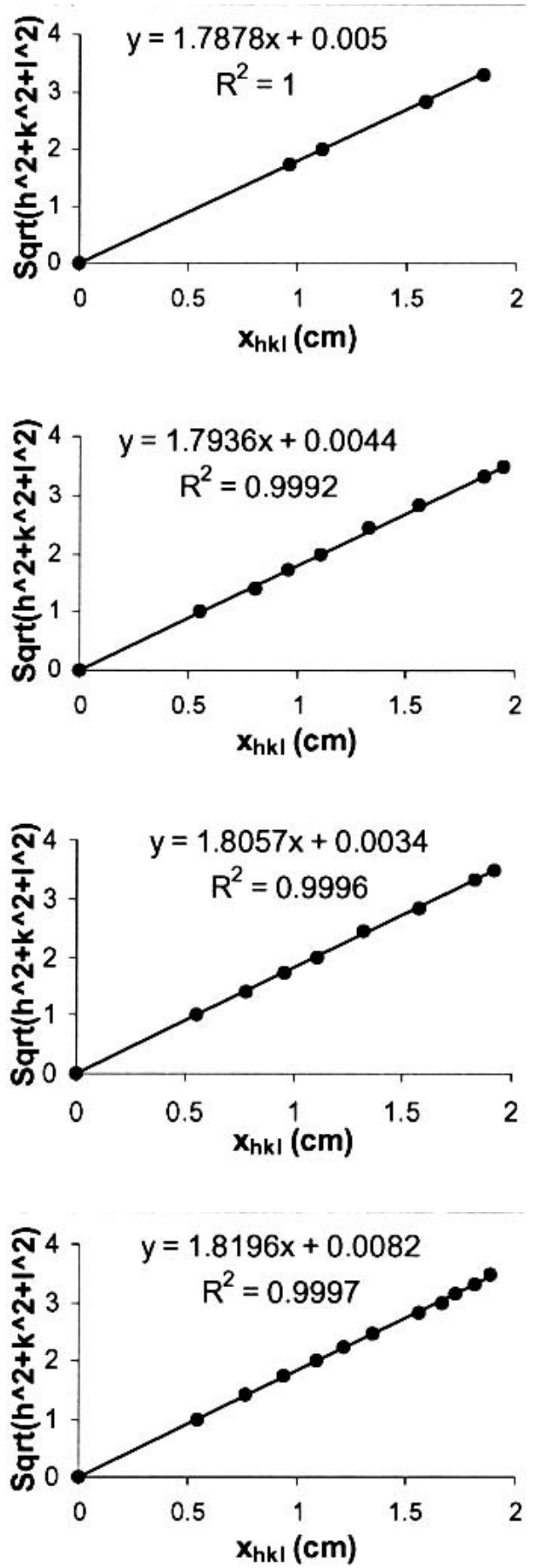

FIG. 10. Indexed SAD patterns (left) and the fits according to Eq. (1) corresponding to the crystallographic structures of a Ni $i_{75 a t . \%} \mathrm{Al}_{25 \text { at.\% }}$ film during isothermal annealing at $500{ }^{\circ} \mathrm{C}$ for (a) $0 \mathrm{~min}$, (b) $20 \mathrm{~min}$, (c) $65 \mathrm{~min}$, and (d) $165 \mathrm{~min}$. 
TABLE II. Values of $x_{h k l}$ measured on photographic prints of SADP for a $\mathrm{Ni}_{75 \text { at.\% }} \mathrm{Al}_{25 \text { at.\% }}$ film during different stages of isothermal annealing at $500{ }^{\circ} \mathrm{C}$.

\begin{tabular}{cccccccc}
\hline \hline & & & & \multicolumn{5}{c}{$x_{h k l} / \mathrm{cm}$} \\
\cline { 5 - 7 }$h$ & $k$ & $l$ & $\sqrt{h^{2}+k^{2}+l^{2}}$ & $t=0 \mathrm{~min}$ & $t=20 \mathrm{~min}$ & $t=65 \mathrm{~min}$ & $t=165 \mathrm{~min}$ \\
\hline $\mathbf{1}$ & $\mathbf{0}$ & $\mathbf{0}$ & 1.000 & - & 0.553 & 0.553 & 0.548 \\
$\mathbf{1}$ & $\mathbf{1}$ & $\mathbf{0}$ & 1.414 & - & 0.813 & 0.787 & 0.763 \\
1 & 1 & 1 & 1.732 & 0.961 & 0.959 & 0.957 & 0.940 \\
2 & 0 & 0 & 2.000 & 1.113 & 1.109 & 1.112 & 1.096 \\
$\mathbf{2}$ & $\mathbf{1}$ & $\mathbf{0}$ & 2.236 & - & - & - & 1.219 \\
$\mathbf{2}$ & $\mathbf{1}$ & $\mathbf{1}$ & 2.449 & - & 1.329 & 1.322 & 1.344 \\
2 & 2 & 0 & 2.828 & 1.584 & 1.561 & 1.576 & 1.559 \\
$\mathbf{2}$ & $\mathbf{2}$ & $\mathbf{1}$ & 3.000 & - & - & - & 1.666 \\
$\mathbf{3}$ & $\mathbf{1}$ & $\mathbf{0}$ & 3.162 & - & - & - & 1.731 \\
3 & 1 & 1 & 3.317 & 1.853 & 1.857 & 1.835 & 1.813 \\
2 & 2 & 2 & 3.464 & - & 1.946 & 1.924 & 1.888 \\
\hline \hline
\end{tabular}

$\sqrt{h^{2}+k^{2}+l^{2}}$ against the corresponding $x_{h k l}$ values for the observable low-order reflections, as tabulated in Table II, verifies a single disordered fcc phase [Fig. 10(a)]. Ordering into the $\mathrm{L}_{2}$ superlattice structure is found to take place after $20 \mathrm{~min}$ of annealing at $500{ }^{\circ} \mathrm{C}$. This is evidenced by the formation of an intensified (100) superlattice reflection ring, which appeared hitherto as a diffused halo in the center of the diffraction pattern at the onset of the $500{ }^{\circ} \mathrm{C}$ heat treatment, as well as the emergence of additional superlattice reflections such as (110) and (211) in the form of discrete spots [Figs. 10(b) and 10(c)]. The transformation from an initially ringed SAD pattern into a spotty appearance also suggests significant grain growth accompanying the ordering progress. Figure 10(d) shows a SAD pattern of the $\mathrm{Ni}_{75 \text { at.\% }} \mathrm{Al}_{25 \text { at.\% }}$ film at $t=165 \mathrm{~min}$. In spite of an exceptional ambiguous spot observed between the (100) and (110) reflections, the satisfactory matching of all the other reflections into the $\mathrm{L1}_{2}$ structure as evidenced by the linear plot of $\sqrt{h^{2}+k^{2}+l^{2}}$ against $x_{h k l}$ indicates that the nanocrystals were fully ordered into the $\mathrm{L}_{2}$ phase after prolonged annealing at $500{ }^{\circ} \mathrm{C}$.

There is a clear trend of lattice expansion recorded for the $\mathrm{Ni}_{75 \text { at.\% }} \mathrm{Al}_{25 \text { at.\% }}$ nanocrystallites as ordering occurs. The lattice parameter $a$ deduced from the slopes of the plots in Fig. 10 according to Eq. (1) had an initial value of $3.59 \AA$ at the onset of the $500{ }^{\circ} \mathrm{C}$ annealing, and it eventually increased to $3.65 \AA$ after an annealing period of 165 min after which full ordering occurred. These are in qualitative agreement with the expected lattice expansion on ordering of the nickel-rich $\gamma$ phase $(a=3.52 \AA)$ into the ordered $\mathrm{L}_{2} \gamma^{\prime}$ phase $(a=3.57 \AA)$ in the bulk condition.

\section{DISCUSSION}

The grain growth of the $\mathrm{Ni}_{75 \text { at.\% }} \mathrm{Al}_{25 \text { at.\% }}$ nanocrystallites measured from our XTEM experiments is of a similar order of magnitude compared with those observed for ball-milled nanocrystalline metallic materials with a similar initial grain size and at comparable temperatures. Varin et al. ${ }^{19}$ reported that ball-milled $\mathrm{L}_{2} \mathrm{TiAl}_{3}$ nanograins initially grew from several nanometers to 30 $100 \mathrm{~nm}$ on annealing at $600{ }^{\circ} \mathrm{C}$ for $1 \mathrm{~h}$, depending on the milling conditions. They used a fast heating rate of $200{ }^{\circ} \mathrm{C} / \mathrm{min}$ in their annealing experiments, and so the heating time to the set-point temperature is negligible compared to the isothermal annealing time they used. The mean grain growth rate in their study can therefore be estimated to be about 30 to $100 \mathrm{~nm} / \mathrm{h}$ at $600{ }^{\circ} \mathrm{C}$. In our $\mathrm{Ni}_{75 \text { at.\% }} \mathrm{Al}_{25 \text { at.\% }}$ films, because of the instrumental limitation of the heating rate to only $20^{\circ} \mathrm{C} / \mathrm{min}$, the heating time to a set-point temperature of $700{ }^{\circ} \mathrm{C}$, for example, was $35 \mathrm{~min}$, and this is not negligible. The data given in Table I suggests that after 25 min of isothermal annealing at $700{ }^{\circ} \mathrm{C}$, the grain size reached approximately $18 \mathrm{~nm}$ from an initial value of about $7 \mathrm{~nm}$. The mean grain growth rate during the first hour of annealing, including the $35 \mathrm{~min}$ of heating-up, is thus roughly $11 \mathrm{~nm} / \mathrm{h}$. Bearing in mind that the mean growth rate during the first hour of heating calculated this way could only increase with a faster heating rate, the grain growth rate of our $\mathrm{Ni}_{75 \text { at.\% }} \mathrm{Al}_{25 \text { at.\% }}$ nanocrystallites can be expected to have a similar order of magnitude as the ball-milled $\mathrm{TiAl}_{3}$ nanograins in the study by Varin et al. ${ }^{19}$ It is also worth noting that the grain size in our $\mathrm{Ni}_{75 \text { at.\% }} \mathrm{Al}_{25 \text { at.\% }}$ film, which was from about $7 \mathrm{~nm}$ as-deposited to a maximum value of about $19 \mathrm{~nm}$ after annealing at $700{ }^{\circ} \mathrm{C}$, is far smaller than the minimum thickness of the TEM disks, which was typically $100-150 \mathrm{~nm}$. The grain growth of the $\mathrm{Ni}_{75 \text { at.\% }} \mathrm{Al}_{25 \text { at.\% }}$ nanocrystallites in our XTEM experiments can therefore be expected to be predominantly three dimensional rather than two dimensional. In other words, the surface effects typical in TEM in situ experiments are not important in the nanocrystalline situation.

The data in Table I suggest that grain growth became very sluggish at large grain sizes. The thermal stability of 
large grain sizes is traditionally ascribed to grainboundary pinning mechanisms that hinder the grain boundary mobility essential for grain growth. As proposed by Burke, ${ }^{17}$ stagnation of grain growth can be attributed to various drag forces acting on grain boundaries due to segregation of second phase particles, impurities, and pores. The pinning mechanism by second phase particles, however, is unlikely to be operative in the nanocrystalline state, leaving impurity or pore drag as the viable mechanisms for the growth stagnation observed in the present films. In fact, nanocrystalline metallic materials are well known to be susceptible to impurity contaminations, especially $\mathrm{C}, \mathrm{N}$, and $\mathrm{O} .^{20-24}$ The segregation of these interstitial contaminants to grain boundaries, and/or the formation of oxides or carbides, were postulated by Morris-Muñoz et al. ${ }^{22}$ and Lee et al. ${ }^{24}$ to have contributed to the grain-size stabilization observed in their nanocrystalline $\mathrm{Fe}-\mathrm{Al}$ and $\mathrm{Ni}$, respectively. In Fig. 2 and in a previous paper, ${ }^{12}$ we reported the observation of a significant amount of oxygen in our nanocrystalline $\mathrm{Ni}_{75 \text { at.\% }} \mathrm{Al}_{25 \text { at.\% }}$ thin films deposited by magnetron sputtering. The absence of oxide phases observable in the $\mathrm{Ni}_{75 \text { at.\% }} \mathrm{Al}_{25 \text { at.\% }}$ films during XRD and TEM characterizations suggests that the oxygen could either be trapped by means of gas-phase physical adsorption or, less likely, form amorphous oxides with the metallic species. We have insufficient information at present to interpret the mechanisms of such a significant oxygen inclusion effect. However, because it is an impurity in nature, the oxygen is likely to play an important role on grain boundary pinning, especially by impurity drag, against the grain growth during the heat treatments of the nanograins.

Impurity drag is well-known to be a grain-size dependent effect, considering the fact that the concentration of impurity segregated at the grain boundaries should increase with the reduction in overall boundary area brought about by grain growth. This implies that grain growth will be retarded as the grain size continues to increase. The kinetics for normal grain growth in our $\mathrm{Ni}_{75 \text { at.\% }} \mathrm{Al}_{25 \text { at.\% }}$ films are found to be consistent with the Burke law in Eq. (2). Although the Burke law was derived based on the assumption of constant driving force, Michels et al. ${ }^{25}$ have recently shown that even when a linear dependence of grain-boundary pinning on grain size is taken into consideration, the resultant graingrowth curve can still be accurately described by the Burke law, albeit a constant rescaling of the boundary mobility parameter $\mathrm{K}$ in Eq. (2). The activation energy calculated from the temperature dependence of the boundary mobility parameter using the Burke law would therefore not be affected by any grain-size dependence of boundary pinning. The activation energy for grain growth in the nanocrystalline $\mathrm{Ni}_{75 \text { at. } \%} \mathrm{Al}_{25 \text { at. \% }}$ is determined to be $1.6 \mathrm{eV}$, which is in good agreement with the value obtained for bulk $\mathrm{Ni}_{3} \mathrm{Al}^{26}$ This suggests that the mechanism for normal grain growth in nanocrystalline $\mathrm{Ni}_{75 \text { at.\% }} \mathrm{Al}_{25 \text { at.\% }}$ is similar to that in the bulk condition.

In addition to normal grain growth, the abnormal growth of certain $\mathrm{Ni}_{3} \mathrm{Al}$ grains has also been observed at elevated annealing temperatures of $500{ }^{\circ} \mathrm{C}$ or higher. A theoretical treatment on two-dimensional abnormal grain growth performed by Rollett and Mullins ${ }^{27}$ yields a complex dependence of abnormal grain growth on the original grain size as well as on the competition between the grain boundary mobility and the grain-matrix interfacial energies. Yet, grain boundary mobility is regarded as the most important factor for the abnormal growth. The occurrence of abnormal grain growth at high temperatures may thus be associated with a restoration of grainboundary mobility for certain grains. This is presumably possible if boundary-dragging species have a low thermal stability and decompose at high temperatures, a case of which has been reported previously. ${ }^{24}$

On the other hand, coalescence in Fig. 7 has been observed to be an operative mechanism for abnormal grain growth. An interesting feature associated with the coalescence process is the rotation of the adjoining grains, presumably required for crystallographic alignment before the subsequent merging of the two grains. Our observation is in good agreement with the work of Haslam et al. ${ }^{28}$ who performed numerical simulation on the growth of nanocrystalline fcc metals and concluded that rotation coalescence is crucial to the growth of nanograins rather than the curvature-driven grainboundary migration alone. The driving force (or torque) for the grain rotation might arise from the tendency of the grains to reduce their overall grain boundary energy due to misorientations. In Fig. 7, one cycle of the grain rotation completes in a few minutes at $800{ }^{\circ} \mathrm{C}$ (note the time scale in Fig. 7). To our knowledge, no such rapid grain rotation has ever been observed in the coalescence of large grains. The reason may be that inertia scales with the volume while the driving force for rotation scales with the surface area. Hence the speed of grain rotation should have a significant size effect; namely, rapid rotation can only occur at very small grain sizes.

Another interesting phenomenon in nanocrystalline $\mathrm{Ni}_{75 \text { at.\% }} \mathrm{Al}_{25 \text { at.\% }}$ thin films is the disorderness in the asdeposited state. De Almeida et al. ${ }^{13}$ have recently studied radio-frequency magnetron sputter deposited $\mathrm{Ni}_{75 \text { at.\% }} \mathrm{Al}_{25 \text { at.\% }}$ thin films, which were found to be ordered into the $\mathrm{L1}_{2}$ equilibrium phase even in the asdeposited state. However, using a low-power dc magnetron sputtering condition as similar to the present experiments, we have found previously that the asdeposited state of similar films is disordered, ${ }^{3,12}$ but ordering into the equilibrium $\mathrm{L}_{2}$ phase follows on annealing. The present results confirm our previous 
finding that as-deposited $\mathrm{Ni}_{75 \text { at.\% }} \mathrm{Al}_{25 \text { at. \% }}$ films made using low-power sputtering indeed have a disordered fcc structure, and ordering follows on heating at $500{ }^{\circ} \mathrm{C}$ or above. The lack of thermal agitation under the low-power sputtering condition is thought to be the reason for not achieving the equilibrium $\mathrm{L}_{2}$ phase in the as-deposited state. Another plausible reason may be that the thermodynamic driving force for ordering may have a size effect; i.e., when the grain size is small enough, surface effects become increasingly important, which may reduce the overall driving force for ordering. A detailed analysis of the relative phase stability between $\gamma$ and $\gamma^{\prime}$ in the nanometer scale would be required to understand this potential effect.

\section{v. CONCLUSIONS}

The normal grain growth kinetics under in situ isothermal heating from 300 to $700{ }^{\circ} \mathrm{C}$ in the TEM were found to obey the Burke growth law. The grain-boundary mobility was found to obey an Arrehnius rate law with an apparent activation energy of $1.6 \mathrm{eV}$, which agreed well with the value in bulk. In addition to the normal grain growth, abnormal grain growth was also observed. Grain coalescence was identified as a mechanism for abnormal grain growth. Rapid grain rotations to achieve crystallographic alignment were observed as a prerequisite step prior to coalescence. The initially as-deposited state of the films was crystalline with a fcc disordered structure. Ordering into the equilibrium $\mathrm{L}_{2}$ superlattice structure followed from annealing at temperatures above approximately $500{ }^{\circ} \mathrm{C}$.

\section{ACKNOWLEDGMENT}

The work described in this paper was supported by a grant from the Research Grants Council of the Hong Kong Special Administrative Region, People's Republic of China, China (Project No. HKU 7077/00E).

\section{REFERENCES}

1. R.N. Wright, J.R. Fincke, W.D. Swank, D.C. Haggard, and C.R. Clark, in Elevated Temperature Coatings: Science and Technology $I$, edited by N.B. Dahotre, J.M. Hampikian, and J.J. Stiglich (Proc. High Temperature Coatings I, TMS, Warrendale, PA, 1995), p. 157.

2. Z. Gonzalez, J.G. Rodriguez, M. Casales, M. Amaya, and L. Martinez, Brit. Corr. J. 36, 65 (2001).
3. H.P. Ng, X.K. Meng, and A.H.W. Ngan, Scripta Mater. 39, 1737 (1998).

4. W.H. Xu, X.K. Meng, A.H.W. Ngan, X.Y. Chen, and Z.G. Liu, Mater. Lett. 44, 314 (2000).

5. C. Leyens, K.H. Trautmann, M. Peters, and W.A. Kaysser, Scripta Mater. 36, 1309 (1997).

6. C. Leyens, J.W. van Liere, M. Peters, and W.A. Kaysser, Surf. Coat. Technol. 108-109, 30 (1998)

7. H.N. Lee, Z.M. Park, M.H. Oh, K.Y. Kim, and D.M. Wee, Scripta Mater. 41, 1073 (1999).

8. C. Leyens, M. Peters, and W.A. Kaysser, Adv. Eng. Mater. 2, 265 (2000).

9. J.M.E. Harper and K.P. Rodbell, J. Vac. Sci. Technol. B 15, 763 (1997).

10. X. Federspiel, F. Voiron, M. Ignat, T. Marieb, and H. Fujimoto, in Advanced Interconnects and Contact Materials and Processes for Future Integrated Circuits, edited by S.P. Murarka, M. Eizenberg, D.B. Fraser, R. Madar, and R. Tung (Mater. Res. Soc. Symp. Proc. 514, Warrendale, PA, 1998), p. 547.

11. J.T. Benoit, S. Chin, R.R. Grzybowski, S.T. Lin, R. Jain, P. McCluskey, and T. Bloom, in Fourth Int. High Temp. Electron. Conf. (IEEE, New York, 1998) p. 109

12. H.P. Ng and A.H.W. Ngan, J. Appl. Phys. 88, 2609 (2000).

13. P. de Almeida, R. Schäublin, A. Almazouzi, M. Victoria, and F. Lèvy, Thin Solid Films 368, 26 (2000).

14. H.P. Ng and A.H.W. Ngan, in Nanophase and Nanocomposite Materials III, edited by S. Komarneni, J.C. Parker, and H. Hahn (Mater. Res. Soc. Symp. Proc. 581, Warrendale, PA, 2000), p. 571.

15. V.L. Tellkamp, S. Dallek, D. Cheng, and E.J. Lavernia, J. Mater. Res. 16, 938 (2001).

16. J.L. Lábár, Proc. EUREM 12, edited by L. Frank and F. Ciampor (Czechoslovak Society for Electron Microscopy, Brno, Czechoslovakia, 2000), p. I379.

17. J.E. Burke and D. Turnbull, Prog. Met. Phys. 3, 220 (1952).

18. X.K. Meng, H. Vehoff, and A.H.W. Ngan, J. Mater. Res. 15, 2595 (2000).

19. R.A. Varin, J. Bystrzycki, and A. Calka, Intermetallics 7, 785 (1999).

20. A. Michels, C.E. Krill, H. Natter, and R. Birringer, in Grain Growth in Polycrystalline Materials III, edited by H. Weiland, B.L. Adams, and A.D. Rollet (TMS, Warrendale, PA, 1998), p. 449.

21. T.R. Marlow and C.C. Koch, Acta Mater. 45, 2177 (1997).

22. M.A. Morris-Muñoz, A. Dodge, and D.G. Morris, Nanostruct. Mater. 11, 873 (1999).

23. M. Jurczyk, K. Smardz, W. Rajewski, and L. Smardz, Mater. Sci. Eng. A 303, 70 (2001).

24. J. Lee, F. Zhou, K.H. Chung, N.J. Kim, and E.J. Lavernia, Metall. Mater. Trans. 32A, 3109 (2001).

25. A. Michels, C.E. Krill, H. Ehrhardt, R. Birringer, and D.T. Wu, Acta Mater. 47, 2143 (1999).

26. M.D. Barò, S. Surinach, J. Malagelada, M.T. Clavaguera-Mora, S. Gialanella, and R.W. Cahn, Acta Metall. Mater. 41, 1065 (1993).

27. A.D. Rollett and W.W. Mullins, Scripta Mater. 36, 975 (1997).

28. J. Haslam, S.R. Phillpot, D. Wolf, D. Moldovan, and H. Gleiter, Mater. Sci. Eng. A 318, 293 (2001). 